$\xi=-1$

\title{
Evaluation and Selection of Poultry Using Probit Method
}

\author{
V.S. Sushkov ${ }^{1 *}$, V. A Babushkin ${ }^{1}$, K.N. Lobanov ${ }^{1}$, N.V. Grihina ${ }^{1}$ \\ ${ }^{1}$ Department of Chemistry, Michurinsk State University of Agriculture, 101 International street, Tambov region, Michurinsk, 393761, \\ Russia \\ *Corresponding author E-mail: v.s.sushkov@mail.ru
}

\begin{abstract}
The purpose of the research is comparative evaluation of fertilizing ability of cocks-breeders in absolute rates (arithmetic mean) and relative (probit), held at egg-laying hens of "Kuchinsky" PBP. Fertilization of eggs, hatchability of eggs and poultry rearing were taken into account during evaluation. Evaluation of cocks in terms of incubation qualities showed that eggs fertilization was $81.4 \%$, hatchability of eggs $-76.6 \%$ poultry rearing $-62.4 \%$. On average one cock fertilized 194.8 eggs, from which 149.3 poults were reared. Biometric processing of incubation qualities identified that influence of cocks was reliable ( $r>0.999)$ on all three indicators, and hatching quality were interconnected, the coefficient of multiple correlation was on the level of 0.939 ( $p>0.999$ ). Comparative evaluation and selection of cocks in absolute terms and with the help of probit-method confirmed high coincidence of their ranks. Rank correlation coefficients between evaluations of these 2 methods of eggs fertilization, hatching and poults rearing was at the level of 0.999-1.000.
\end{abstract}

Keywords: Eggs fertilization, poults rearing, probit-method, correlation.

\section{Introduction}

In poultry industry, the problem of objective evaluation of parents strain merits, selection and picking up their descendants for further breeding is caused by several reasons. A general reason is limited possibility to segregate the influence of paratypic factors in evaluation of genotype [1]. Particular reasons can be referred to the small number of hens per rooster. So, according to researchers there are 2.03-8.7 hen and 2.6-20.1 descendants per one six week age cock, and -1.22-2.85 descendants per one hen. [2-3]. On OSS PBP "Kuchinsky" laying eggs in the incubator is realize-d in proportion of one cock for 10 hens, thereby increasing the probability of assessment accuracy [4-5].

During evaluation and selection of poultry with desirable productivity is most often used absolute figures (arithmetic mean of feature, for example, live weight of poultry at a certain age, average $\%$ poults rearing, etc.). In another study [6] it is noted that selection on features with low value of heredity coefficients is ineffective. The author believes that the animal breeding value estimation accuracy can be improved by attracting additional information on productivity of closest relatives (ancestors, lateral relatives, descendants).

It was also found that when distribution of traits in a population is asymmetric, using traditional methods of estimating selection boundaries and mean values for a chosen reproduction group is accompanied by a considerable mistake in defining selection differential and selection effect.

In addition to absolute indicators, relative values are also taken into account. They clarified evaluation and increased objectivity and reliability of most productive poultry selection.

Relative values allow to compare generations of birds with fewer amount of errors, that occur when location and time is changed. Relative values attract more often. They were obtained from dividing the indicators of evaluated poultry into the same indicators, describing average data on coeval groups, lines, etc. [7].
Of all proposed methods, preference was given to probit-relative value, allowing to judge about phenotypic digression of evaluated individual features from the same feature average values expressed in fractions of average standard quadratic deviation. It is known that offspring quality evaluation made by manufacturer and based on absolute and relative indicators (probit) is the most exact on genotype.

\section{Materials and methods}

To accomplish this task there were analyzed results of cocks evaluation from the whole group $(n=120)$, as well as selection from it $(n=12)$. As a kind of breeders genotype evaluation it was used the method of comparing their descendants with coevals, besides absolute indicators (arithmetic mean of the feature mean square deviation $-X,-a$ ), thee was evaluated relative-probit, that was calculated using the following formula:

$P=\left(X_{i}-X\right) / a+5$,

where: $P$ - probit; $X_{i}$ - quantity of evaluated individual feature; $X$ - the average value of the feature among coevals of one group, line; $<J$ - mean square deviation of the coevals population group. When evaluating breeder-cocks it was taken into consideration incubation qualities that were calculated in accordance with the methodology of VNITIP (2000) using the following formulas:

- fertilization of eggs - by dividing the number of fertilized eggs on the number of eggs laid in the incubator, \%;

- the hatchability of eggs - by dividing the number of hatched conditional offspring on the number of fertilized eggs, laid in the incubator, \%;

- poults rearing - by dividing the number of reared conditional offspring on the number of all eggs laid for incubation, (\%).

In addition to the above-mentioned genetic-statistical parameters, expected phenotypic correlation coefficients were calculated. For 
evaluation of results biometric processing there were used methods described in studies by E.K. Merkuryeva [8] and G.F. Lakina [9].

\section{Results}

Genetic-statistical analysis of roosters reproductive ability are summarized in Table 1. It follows from table 1 that from one rooster there was laid for incubation 180-295 eggs, or egg 239.4 average, variability was $-9.82 \%$. There were fertilized 198 eggs on cock in average with the variability of $18.5 \%$. 148 poults received, variability was high $-26.9 \%$.

Presented in Figure 1 linear curves of 111 roosters distribution better illustrate the breeding frequency depending on the class of incubation qualities. Figure 2 shows that the highest frequency of cocks on hatchability and poultry rearing ( $F=22-23$ heads) falls on modal (medium) class or on the 6-th, and the 7-th class on fertilization (frequency 17 cocks, they had this rate at the level of an average $86.5 \%$ ). On eggs hatchability and poultry rearing $22-23$ cocks showed 73.9 and $63.3 \%$ properly.

We have calculated the phenotypic correlations rates (Table 2).

Table 1: Statistical parameters of cocks reproductive ability

\begin{tabular}{lcccccccc}
\hline Indicators & $n$ & $\max$ & $\min$ & $\dot{X} \pm m$ & $a$ & $C_{v}$ \\
\hline $\begin{array}{l}\text { Laid in the incubator } \\
\text { per 1 rooster, eggs }\end{array}$ & 120 & 295 & 180 & $239.4 \pm 2.14$ & 23.5 & 9.82 \\
$\begin{array}{l}\text { Fertilization from } \\
\text { one rooster, eggs }\end{array}$ & 120 & 266 & 63 & $198 \pm 3.34$ & 36.5 & 18.5 \\
$\begin{array}{l}\text { Offspring rearing from } \\
\text { one rooster, head. }\end{array}$ & 120 & 223 & 22 & $148 \pm 3.63$ & 39.8 & 26.9 \\
$\begin{array}{l}\text { Fertilization ofeggs, \% } \\
\text { Hatchabilityofeggs, \% }\end{array}$ & 111 & 96.2 & 67.1 & $84.3 \pm 0.68$ & 7.25 & 8.6 \\
Poultsrearing, \% & 111 & 85.1 & 51.6 & $76.1 \pm 0.75$ & 7.93 & 10.4 \\
& & & & & $64.3 \pm 1.01$ & 10.65 & 16.6 \\
\hline
\end{tabular}

Table 2: Coefficients of phenotypic correlations on incubation qualities of eggs

\begin{tabular}{|c|c|c|c|c|}
\hline Indicators & $n$ & $r$ & $m_{s}$ & $P$ \\
\hline $\begin{array}{l}\text { Fertilization of eggs }(X)- \\
\text { hatchability of eggs }(Y)\end{array}$ & 111 & 0.310 & 0.08 & $>0.99$ \\
\hline $\begin{array}{l}\text { Fertilization of eggs }(X)- \\
\text { poultry rearing }(Z)\end{array}$ & 111 & 0.605 & 0.06 & $>0.999$ \\
\hline $\begin{array}{l}\text { Hatchability of eggs }(Y)- \\
\text { poultry rearing }(Z)\end{array}$ & 111 & 0.870 & 0.02 & $>0.999$ \\
\hline $\begin{array}{l}\text { The total correlation coefficient } \\
\text { of three conjugated figures }\end{array}$ & 111 & 0.939 & 0.06 & $>0.999$ \\
\hline
\end{tabular}

As table 2 data demonstrated, all calculated rates were highly reliable. The highest link is determined between hatching of eggs and rearing poultry, i.e. mortality (frozen, addle eggs) at this incubation stage was negligible.

The lowest connection index: fertilization of eggs - hatchability of eggs make out 0.310 , although it was reliable $(r>0.99)$. At this stage of incubation accounting there were unfertilized eggs with bloody ring and other causes of mortality. Suffice to say that, on average, from 329.4 eggs laid in incubation from each rooster, the fertilized amounted was 198 eggs at variability of this rate $C_{v}=9.8 \%$.

Reliable in all aspects of communications and a relatively high level on grounds such as fertilization of eggs - poultry rearing, hatchability of eggs - poultry rearing, multiple correlation coefficient of these three figures allows you to conclude that cocks can be evaluated and selected by one from incubation qualities - poultry rearing.

Modern cross egg-laying hens have high egg productivity, which reached selection plateau in some of them. Evaluation and selection of poultry in absolute terms doesn't give reliable effect, especially when ranking it in modal class. To get an objective evaluation of the reproductive ability of cocks in modal class, there were compared estimates obtained in absolute values and probit (Table 3 and 4$)$.

Table 3: Incubation qualities of cocks

\begin{tabular}{c|c|c|c|c|c|c|c|c}
\hline \multirow{2}{*}{ № $\mathrm{p} / \mathrm{p}$} & \multirow{2}{*}{ № cock } & \multicolumn{2}{c|}{ Fertilization of eggs, \% } & \multicolumn{2}{c|}{ Hatchability of eggs, \% } & \multicolumn{2}{c|}{ Poultry rearing, \% } & \multirow{2}{*}{ Places total } \\
\cline { 3 - 7 } & & $X \pm m$ & rank & $X \pm m$ & rank & $X \pm m$ & rank & \\
\hline 1 & 1 & $95 \pm 1.36$ & 2 & $89.8 \pm 1.93$ & 1 & $85.3 \pm 2.20$ & 1 & 4 \\
2 & 6 & $94.4 \pm 1.40$ & 4 & $86.7 \pm 2.13$ & 3 & $81.9 \pm 2.40$ & 4 & 11 \\
3 & 11 & $94.7 \pm 1.38$ & 3 & $87.3 \pm 2.10$ & 2 & $82.6 \pm 2.33$ & 2.5 & 7.5 \\
4 & 16 & $96.2 \pm 1.20$ & 1 & $85.8 \pm 2.19$ & 4 & $82.6 \pm 2.33$ & 2.5 & 7.5 \\
5 & 20 & $82.7 \pm 2.40$ & 7 & $79.2 \pm 2.82$ & 7 & $65.1 \pm 3.00$ & 8 & 22 \\
6 & 22 & $85.8 \pm 2.29$ & 5 & $77 \pm 2.98$ & 8 & $66.1 \pm 3.10$ & 7 & 20 \\
7 & 24 & $82.1 \pm 2.30$ & 8 & $83 \pm 2.48$ & 6 & $68.1 \pm 3.08$ & 6 & 20 \\
8 & 31 & $84.7 \pm 2.28$ & 6 & $83.9 \pm 2.53$ & 5 & $71.1 \pm 3.32$ & 5 & 16 \\
9 & 36 & $72.2 \pm 2.95$ & 9 & $75,9 \pm 3,32$ & 9 & $54.8 \pm 3.28$ & 9 & 27 \\
10 & 69 & $72.0 \pm 2.76$ & 10 & $67.4 \pm 3.40$ & 10 & $48.5 \pm 3.07$ & 10 & 30 \\
11 & 176 & $71.3 \pm 3.13$ & 11 & $61.7 \pm 3.50$ & 11 & $44 \pm 3.43$ & 11 & 33 \\
12 & 209 & $70.8 \pm 3.12$ & 12 & $60 \pm 4.00$ & 12 & $42.5 \pm 3.40$ & 12 & 36 \\
Inaverage & & $84 \pm 0.67$ & - & $79.7 \pm 0.80$ & - & $67 \pm 0.86$ & - & - \\
\hline
\end{tabular}

Table 4: Evaluation of cocks incubation qualities using probit-method

\begin{tabular}{|c|c|c|c|c|c|c|c|c|}
\hline \multirow{2}{*}{ № p/p } & \multirow{2}{*}{ № cock } & \multicolumn{2}{|c|}{ Fertilization of eggs, $\%$} & \multicolumn{2}{|c|}{ Hatchability of eggs, $\%$} & \multicolumn{2}{|c|}{ Poultry rearing, \% } & \multirow{2}{*}{ Places tota } \\
\hline & & probit & rank & probit & rank & probit & rank & \\
\hline 1 & 1 & 5.33 & 2 & 5.28 & 1 & 5.43 & 1 & 4 \\
\hline 2 & 6 & 5.31 & 4 & 5.19 & 3 & 5.35 & 4 & 11 \\
\hline 3 & 11 & 5.32 & 3 & 5.21 & 2 & 5.37 & 2 & 7 \\
\hline 4 & 16 & 5.36 & 1 & 5.17 & 4 & 5.36 & 3 & 8 \\
\hline 5 & 20 & 4.94 & 7.5 & 4.98 & 7 & 4.96 & 8 & 22.5 \\
\hline 6 & 22 & 5.05 & 5 & 4.92 & 8 & 4.98 & 7 & 20 \\
\hline 7 & 24 & 4.94 & 7.5 & 5.09 & 6 & 5.03 & 6 & 19.5 \\
\hline 8 & 31 & 5.02 & 6 & 5.11 & 5 & 5.10 & 5 & 16 \\
\hline 9 & 36 & 4.65 & 9 & 4.90 & 9 & 4.72 & 9 & 27 \\
\hline 10 & 69 & 4.64 & 10 & 4.67 & 10 & 4.57 & 10 & 30 \\
\hline 11 & 176 & 4.63 & 11 & 4.52 & 11 & 4.47 & 11 & 33 \\
\hline 12 & 209 & 4.61 & 12 & 4.48 & 12 & 4.44 & 12 & 36 \\
\hline
\end{tabular}


Table 3 shows that eggs fertilization exponent of 12 cocks and egg-laying hens 88 practically coincides with the average figure of fertilization in all group $(84 \pm 0.67, n=120$ and $84.3 \pm 0.68$, $\mathrm{n}=111$ ). I.e., patterns, obtained on $10.8 \%$-selection can be correlated with the whole group of evaluated cocks. It was found that roosters-breeders who have these qualities differed far from average and received the highest or the lowest rate. Thus, roosters with code numbers $36,69,176$ and 209 were ranked respectively 9,10 , 11,12 places. They will be displayed from the brood, as so-called «negative options». The recent had incubation qualities respectively: eggs fertilization $-70-72 \%$, hatchability of eggs $-60-76 \%$ poultry rearing $-42.5-54.8 \%$. The roosters «positive-options» $(1,6,11,16)$ with these qualities, respectively took first places at the level of $94.4 \%-96.2,85.8 \%-89.8$ and $81.9 \%-85.3$ so they remain for further reproduction. It is harder to evaluate and select poultry that is part of modal class, i.e., where there is the largest number of them with average incubating qualities. Here the amount of places (16) best became cock 31 with incubating qualities $84.7 ; 83.9 ; 71.1 \%$ and $24-82.1 ; 83.0 ; 68.1 \%$.

Probit calculations showed (table 4 ) that roosters-breeders from «positive-options» group occupied the top places on the relative values of probit, related to the standard deviation for cocks evaluation $(n=111)$.

These include cocks $1 ; 6 ; 11 ; 16$ having total places on probit respectively $4 ; 11 ; 7.5$ and 7.5 . Most places were taken by roosters from the group of negative-options. They are 36; 69; 176 and 209 who took last places during evaluation and the total places were distributed respectively 27, 30, 33 and 36 . As for the modal class, roosters 31 and 24 were evaluated best, same as for absolute incubation qualities. Probit calculations revealed that redistribution of cocks places almost didn't happen. However, with the help of probit-method it is possible to differentiate cocks evaluation in a modal class, that is difficult when evaluating and selecting in absolute figures. Reliability of probit-method evaluation in the modal class increases with decreasing diversity of features variety, but with the increase of mean square deviation, differences in probit between cocks become minimal. It can lead to inaccuracies in selecting poultry for the brood.

\section{Discussions}

Evaluation of cocks in terms of incubation qualities showed that eggs fertilization was $81.4 \%$, hatchability of eggs $-76.6 \%$ poultry rearing $-62.4 \%$. On average, one cock fertilized 194.8 eggs, from which 149.3 poults were reared.

Biometric processing of incubation qualities identified that influence of cocks was reliable $(r>0.999)$ on all three indicators, moreover they were interconnected. The coefficient of multiple correlation was on the level of $0.939(p>0.999)$. Therefore, from 3 studied interconnected indicators, evaluation and selection can be processed using poultry rearing.

Comparative evaluation and selection in absolute figures and their probit confirmed high coincidence, i.e., selection can be successfully processed using probit-method because this method better differentiates ranks of cocks brood qualities in a modal (middle class).

\section{Conclusion}

To increase the objectivity of poultry evaluation and selection, together with evaluation of absolute values, there should be applied a relative fgure - probit-method, allowing to differentiate evaluation of poultry in the modal class more exactly. It is also necessary to improve egg incubation technology to increase poultry hatching significantly.

\section{References}

[1] Smetnev SI (1978), Poultry. Ed.6-e,Rev.and additional. Moscow: Kolos, 304 p.

[2] Dmitriev V, Gal'peri I, Suchkov O (2003), New principle poultry brood qualities evaluation. Poultry farming, 4: 6-8.

[3] Kochish II, Petrash MG, Smirnov SB (2003), Poultry farming. Moscow: Kolos, 405 p.

[4] Varentsova ZM, Annenkova MN, Nikolskya VV et al. (2005), Guidelines for working with whiteshellegg cross poultry of "Hisex White R" selected by «Kuchinsky», $81 \mathrm{p}$.

[5] Imangulov SA, Egorov IA, Okolelova TM et al. (2000), The methodology of scientifc and industrial research on poultry nutrition. Recommendations, 19.

[6] Kontarev IV (2006), Optimization and modeling methods of poultry brood selection in poultry farming, $20 \mathrm{p}$.

[7] Bogolyubskiy SI (1991), Selection of poultry. Tutorial. Moscow: VO Agropromizdat, $284 \mathrm{p}$.

[8] Merkuryeva EK, Abramov ZV, Bukay AV et al. (1991), Genetics and Biometrics. Moscow, p 444.

[9] Lakin NF (1980), Biometrics. Moscow: High school, $291 \mathrm{p}$. 